\title{
Las torres parroquiales del Condado de Niebla tras el terremoto de Lisboa
}

Juan Miguel González Gómez, Jesús Rojas-Marcos González | Departamento de Historia del Arte, Universidad de Sevilla

URL de la contribución <www.iaph.es/revistaph/index.php/revistaph/article/view/3645>

\section{RESUMEN}

En el presente estudio reseñamos doce torres parroquiales, afectadas por el luctuoso movimiento sísmico de 1755 , en el Condado de Niebla. Con tal motivo, unas fueron consolidadas y remodeladas y otras construidas de nueva planta. Todas corresponden a la tipología arquitectónica sevillana de la segunda mitad del Setecientos. Por tanto, constan de fuste o caña, cuerpo de campanas y chapitel facetado recubierto de azulejería. Hay una excepción, usual en el valle del Guadalquivir en esa centuria, la de Chucena, que reproduce esquemáticamente la famosa Giralda de Sevilla. Además de ésta, son de nueva fábrica las de Bollullos par del Condado, La Palma del Condado, Manzanilla y Trigueros.

\section{Palabras clave}

Arquitectura | Barroco. Siglo XVIII | Huelva (Provincia) | Iglesias parroquiales | Sevilla (Provincia) | Torres | 


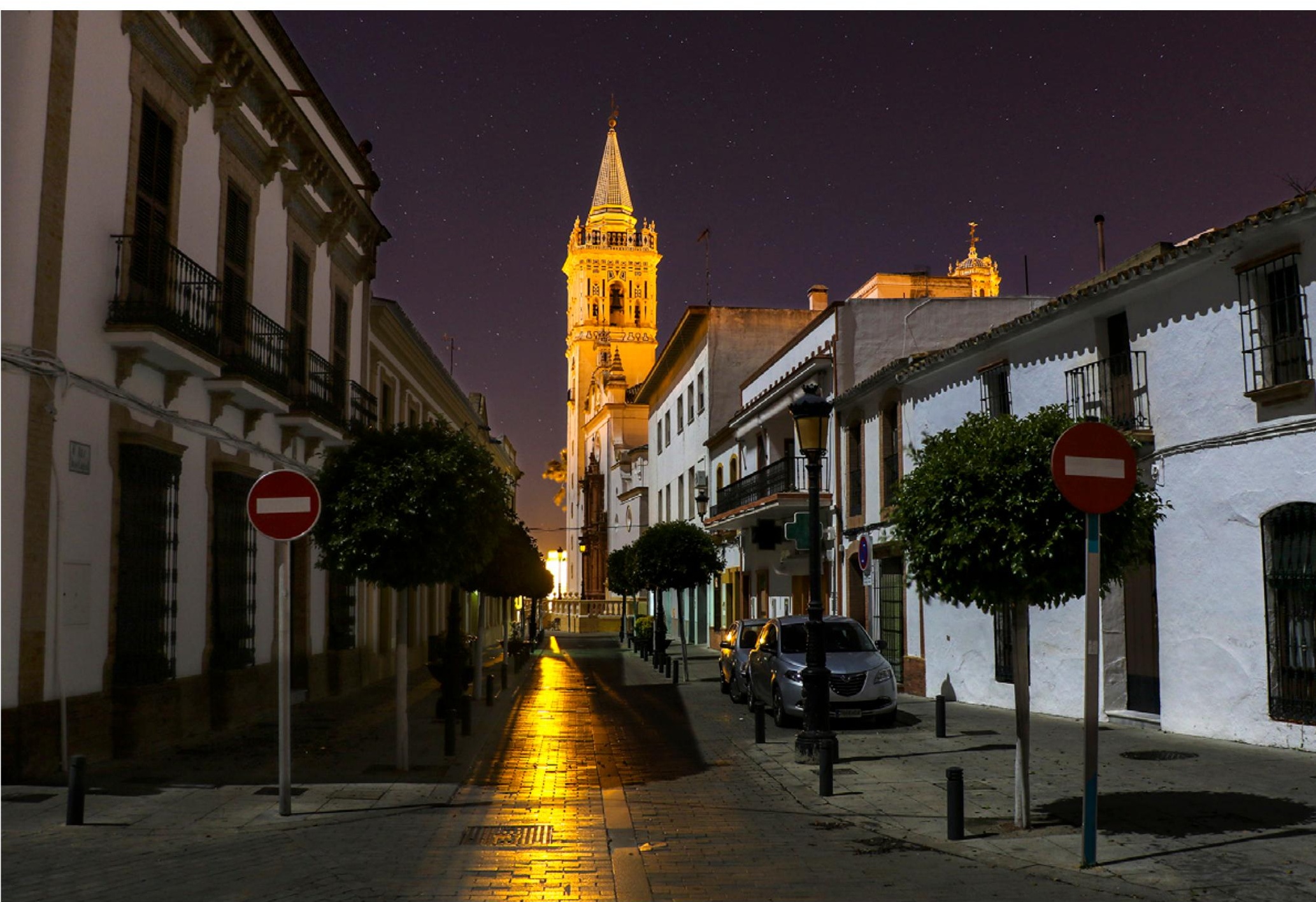

Calle Rey Juan Carlos I de La Palma del Condado con la iglesia parroquial de San Juan Bautista al fondo | foto Antonio José Alcalde Pérez 
La parroquial de la Asunción de Almonte es un templo mudéjar de los siglos $X V$ y XVI. Su escueta torre contribuye al equilibrio de masas y distribución de volúmenes en la fachada principal. Apenas despunta a la derecha del imafronte. Sobre la encalada caña se yergue el cuerpo de campanas. Por cada lado del campanario hay un arco de medio punto, con campana, y antepecho de hierro, entre pareadas pilastras que reciben el correspondiente entablamento, también apilastrado. Sobre él se dispone un banco con similar formato. Y, sobre otro banco octogonal, se alza el usual chapitel facetado de azulejería sevillana. Esta torre se atribuye a Antonio Matías de Figueroa, al reproducir su típica distribución de elementos.

En el contorno de la parroquial de San Bartolomé de Beas destaca la torre, una de las más altas de la provincia, cuyo remate fue reconstruido tras el seísmo de Lisboa. Se yergue voluminosa en la cabecera de la nave de la epístola del templo. Se compone de caña, cuerpo de campanas y chapitel. Responde al gusto finisecular del Setecientos. La veleta, fechada en 1829, marca la finalización de las obras. La torre parroquial de Santiago Apóstol de Bollullos par del Condado, del último cuarto del siglo XVIII, sustituyó a otra anterior que estuvo en uso hasta 1776. Entonces, Antonio Matías de Figueroa acometió la ampliación del templo. En el informe del referido arquitecto, de 15 de marzo de 1779, se anota que había levantado la torre hasta la imposta de los arcos del campanario. Las obras se paralizaron durante quince años. En 1795 ya estaba concluida. La torre actual, que despunta verticalmente a la derecha del imafronte, está compuesta de caña, cuerpo de campanas y chapitel. En la zona central del fuste o caña hay tres pequeños vanos y, más arriba, un balcón con antepecho de hierro forjado.

En la parroquial de la Asunción de Bonares se yergue, a los pies del templo, una torre fachada, que quedó inutilizable tras el terremoto de 1755 . De planta rectangular, se compone de caña, campanario y chapitel. Hoy está enmascarada por las construcciones que a principios del siglo XX se adosaron a ella. La pequeña y escueta torre de la parroquial de la Estrella de Chucena, del último tercio del Setecientos, se adosa al crucero por el lado de la epístola. Compuesta de caña y campanario, está inspirada en el prototipo de la Giralda sevillana. En la parroquia del Divino Salvador de Escacena se construyó una torre fachada, cuyo cuerpo inferior, que da acceso al templo, se cubre con bóveda vaída. Tras el seísmo de Lisboa se arregló su techumbre y se compuso su aguja.

El templo parroquial de San Juan Bautista de La Palma quedó arruinado tras el terremoto de 1755. Su torre, ligada a la de Bollullos par del Condado, se alza a la derecha del imafronte. La caña, cúbica, presenta estrechos vanos con recortados marcos. En cambio, el cuerpo de campanas aparece profusamente decorado. De su quebrado basamento penden recortados pinjantes. Un apiramidado chapitel, recubierto de azulejería sevillana, sobre banco 

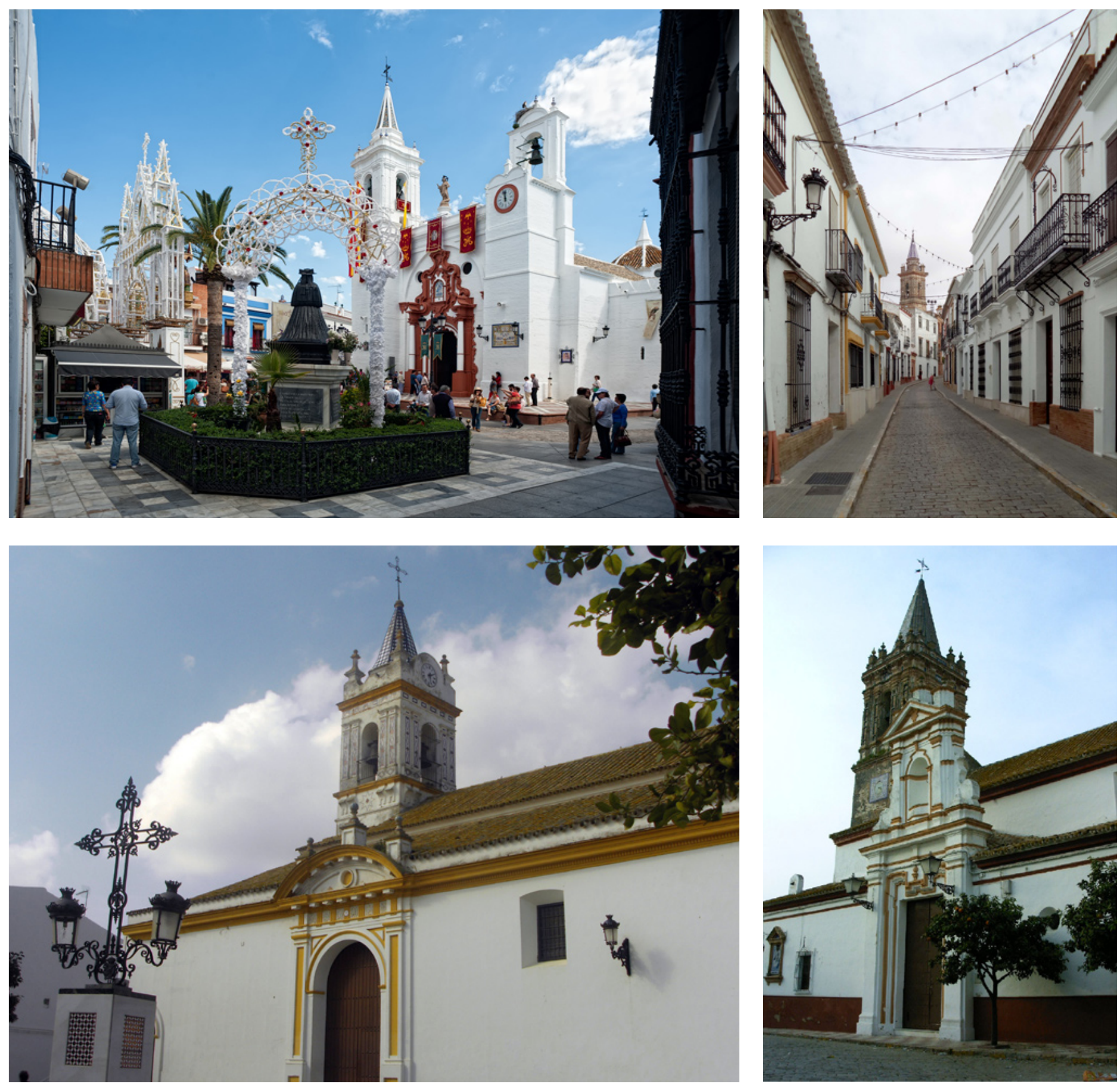

Monumento a la virgen del Rocío en Almonte situado en la Plaza del mismo nombre, frente a la iglesia parroquial de la Asunción | foto José Gil Paradas

Calle de Bollullos par del Condado con la iglesia parroquial de Santiago Apóstol al fondo | foto Juan José Raposo González

Iglesia parroquial de la Asunción de Bonares | foto Pueblos de Huelva Iglesia parroquial del Divino Salvador de Escacena | foto Miguel Ángel Acosta Delgado 

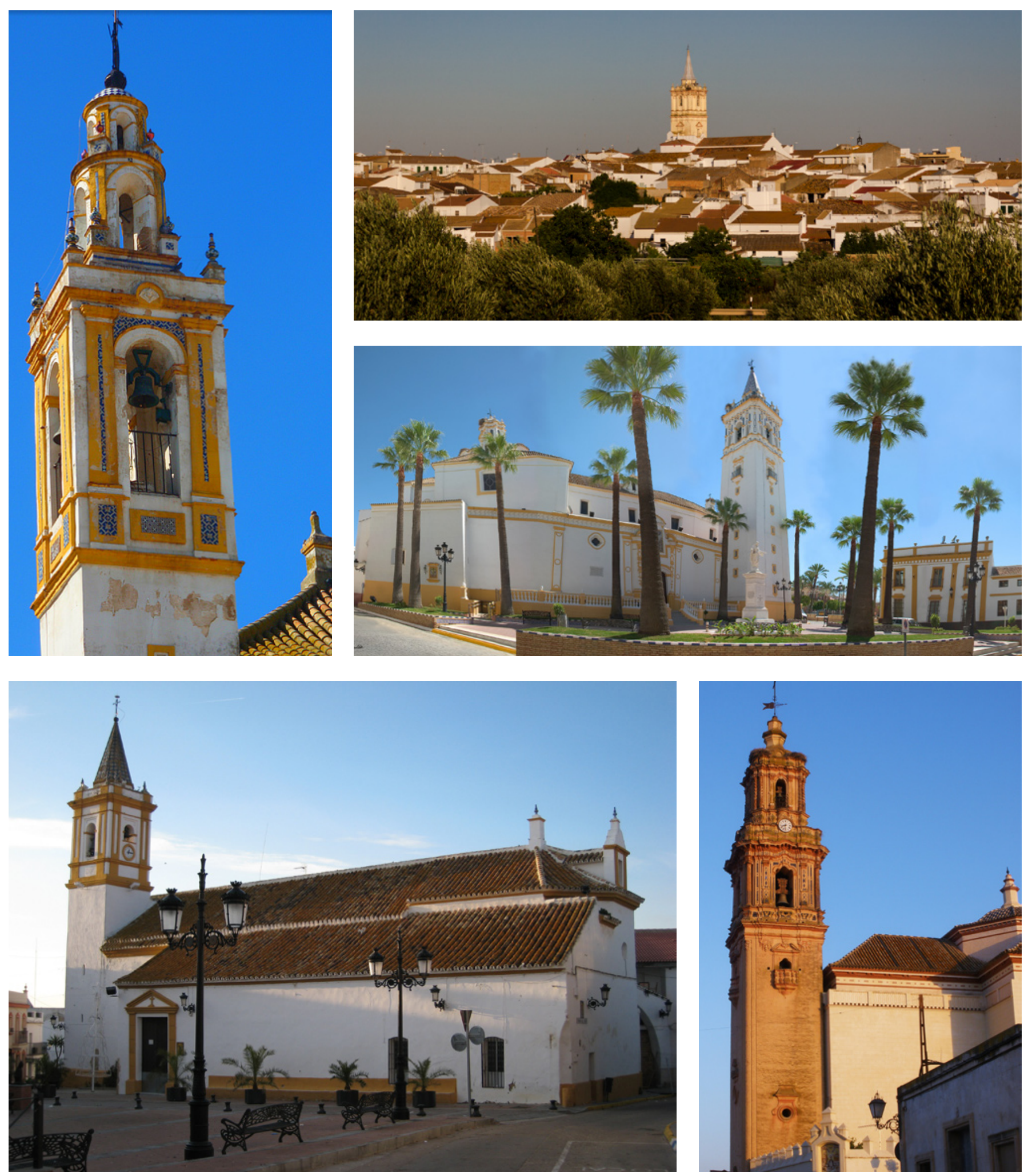
ochavado, corona la torre. Según Sancho Corbacho es típico de Antonio Matías de Figueroa. La torre de la parroquia de San Vicente Mártir de Lucena del Puerto, obra de Pedro de Silva (1759-1760), se eleva a los pies del templo, en el ángulo suroeste de su única nave. La caña ostenta pequeños y estrechos vanos rectangulares. El cuerpo de campanas presenta por cada flanco un solo arco de medio punto con impostas, flanqueado por dos pilastras cajeadas, que reciben un esquemático entablamento. Sobre él se alza un antepecho de idéntico formato. Remata el total un chapitel revestido de azulejería sevillana. En su vértice exhibe una bola y una cruz de cerrajería.

La torre parroquial de Ntra. Sra. de la Purificación de Manzanilla, rematada en 1779, es obra de Lucas Cintora y Francisco Díaz Pinto. Puede considerarse como una de las más bellas de la provincia onubense. Ubicada en la cabecera del templo, se compone de caña, dos cuerpos de campanas, superpuestos y decrecientes, y un chapitel. Todo el conjunto tectónico, de gran riqueza ornamental, está construido en ladrillo limpio, tallado, con azulejos embutidos. Los dos cuerpos de campanas se enriquecen con verduguillos azules. El inferior, con banco y antepecho de pedestales y balaústres ondeados, abre por cada flanco un vano con arco mixtilíneo flanqueado por pilastras de orden jónico. En los ángulos achaflanados aparecen sencillas columnas jónicas. Pilastras y columnas que soportan un movido entablamento sobre el cual monta el citado antepecho. El cuerpo superior adopta semejante distribución, pero en sus ángulos achaflanados lucen columnas salomónicas pareadas de orden corintio, quizás los ejemplares más tardíos
Torre de la iglesia parroquial de la Estrella en Chucena | foto José Antonio Cardoso

Localidad de Beas y la torre de su iglesia parroquial de San Bartolomé | foto Juan Luis González Rodríguez

Plaza del Corazón de Jesús e iglesia de San Juan Bautista de La Palma del Condado | foto Antonio José Alcalde Pérez

Torre de la iglesia parroquial de San Vicente Mártir en Lucena del Puerto | foto Antonio Pérez (SKaRCHa)

Torre de la iglesia parroquial de Ntra. Sra. de la Purificación de Manzanilla | foto Juan Luis Romero

Iglesia parroquial de San Antonio Abad de Trigueros | foto M. ${ }^{\text {a }}$ Carmen Rafallo Bautista

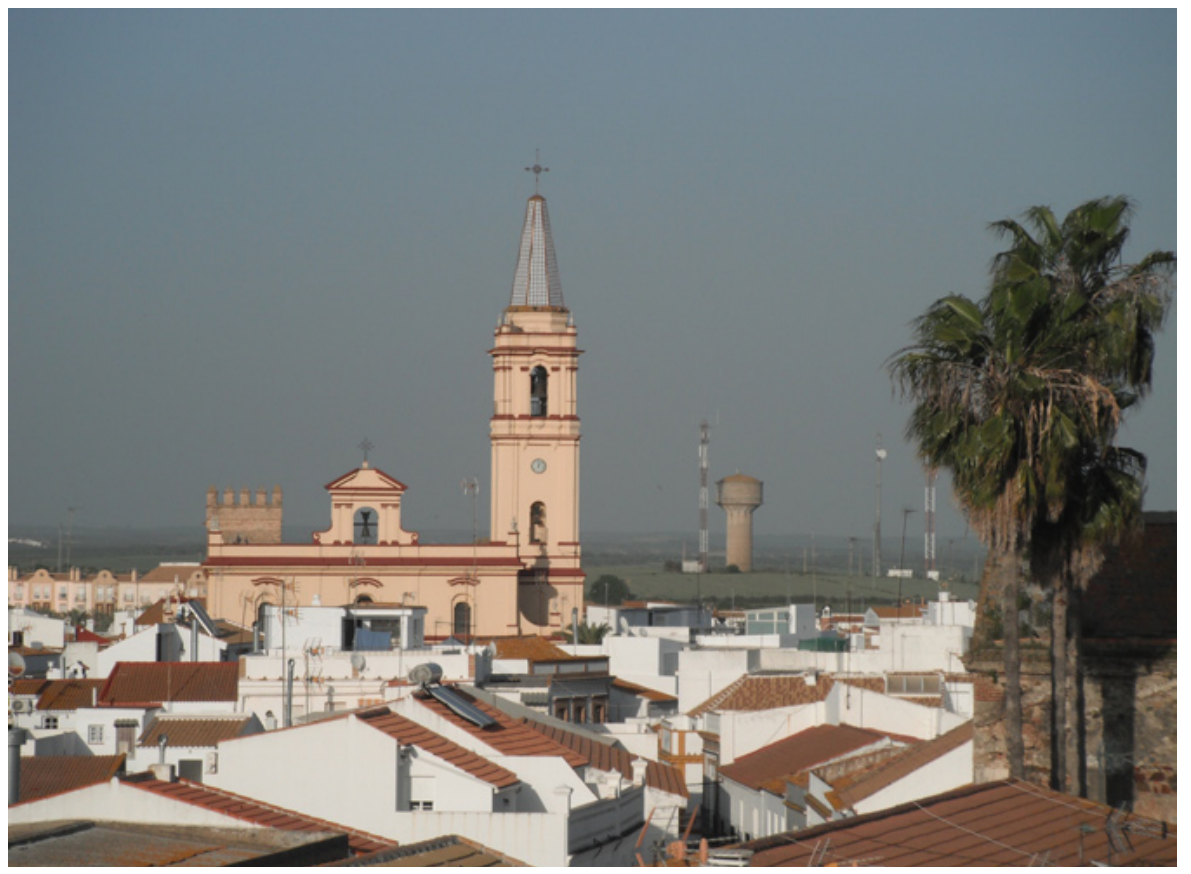


Torre de la iglesia parroquial de San Bartolomé Apóstol (Paterna del Campo) | foto María José Sánchez Morato

Torre de la iglesia parroquial de San Vicente Mártir en Villarrasa | foto José Antonio Cardoso
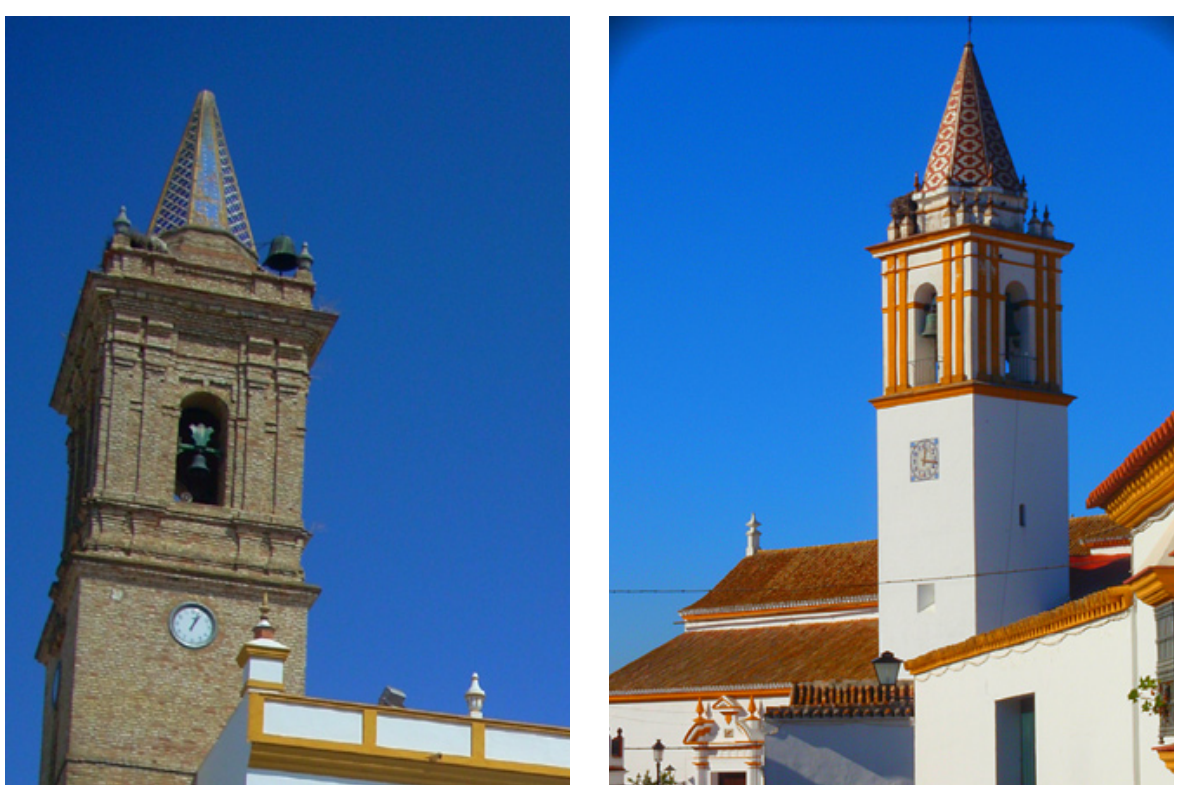

de este tipo de soportes. El chapitel, de curioso formato, contrasta vivamente con la riqueza ornamental de los dos cuerpos de campanas. Sus recortados perfiles y acusadas estrangulaciones configuran su singular morfología, confirmando la diferente autoría.

La torre fachada de la parroquial de San Bartolomé de Paterna del Campo se alza sobre la puerta de los pies de la iglesia. Su organización general es propia de las postrimerías del Gótico y el comienzo del Renacimiento, muy difundido a lo largo del siglo XVI por la provincia de Sevilla. Se decora con una sencilla imposta y arcos ciegos lobulados, y de herradura apuntados en el segundo cuerpo. Con motivo del terremoto de Lisboa se arruinaron los dos cuerpos y su aguja o chapitel, que fueron reconstruidos por Pedro de San Martín y Mateo de Alba, a quienes atribuimos el cuerpo de campanas.

La torre del templo parroquial de San Antonio Abad de Trigueros se erigió tras el seísmo de 1755. En 1780 se fecha su campanario, que se alza sobre un banco de pedestales bulbosos, con un vano en cada frente, flanqueado por pilastras jónicas. En cada esquina presenta dos columnas del mismo orden, que recuerdan a la citada torre de Manzanilla. El total se corona con un chapitel facetado, recubierto de azulejería, cuya cruz se colocó en 1794. Por último, la torre de la parroquia de San Vicente Mártir de Villarrasa, elevada en la cabecera junto a la nave lateral izquierda, sufrió grave quebranto en el terremoto de Lisboa. Su caña, desornamentada, remite al cuerpo de campanas, que presenta por cada flanco un arco de medio punto flanqueado por sendas pilastras pareadas. Un banco, con dados y jarras, suaviza el tránsito al chapitel poligonal con azulejería polícroma. 


\section{BIBLIOGRAFÍA}

- ANGULO ÍÑIGUEZ, D. (1932) Arquitectura mudéjar sevillana. Sevilla: sn, 1932 (Imp. Gráficas Marianas)

- BECERRIL PÉREZ, D. L. (1998) La Torre y la Parroquia de San Bartolomé. Cinco siglos de Historia y Arte en Beas. Beas (Huelva): Ayuntamiento, 1998

- BONET CORREA, A. (1978) Andalucía Barroca. Barcelona: Polígrafa, 1978

- FALCón MÁRQUEZ, T. (1977) Documentos para el estudio de la arquitectura onubense. Huelva: Diputación Provincial, 1977

- GONZÁlEZ GóMEZ, J. M.; CARRASCO TERRIZA, M. J. (1999) Catálogo Monumental de la Provincia de Huelva. Huelva: Universidad de Huelva, 1999, vol. I

- GONZÁLEZ GÓMEZ, J. M.; CARRASCO TERRIZA, M. J. (2006) Tierra Llana Oriental. En Guía artística de Huelva y su provincia. Sevilla: Fundación José Manuel Lara y Diputación Provincial de Huelva, 2006, pp. 309-500

- HERNÁNDEZ díAZ, J. (1946) La ruta de Colón y las torres del Condado de Niebla: estudio histórico artístico. Madrid: Instituto de Cultura Hispánica, 1946 (Serie Cuadernos de Arte, vol. I)

- KUBLER, G. (1957) Arquitectura de los siglos XVII y XVIII. Madrid: Plus Ultra, 1957 (Ars Hispaniae; vol. X)

- Llaguno Y AMíRolA, E. (1829) Noticias de los Arquitectos y Arquitectura de España. Madrid: Imprenta Real, 1829, tomo IV

- MENDIOROZ LACAMBRA, A. (1993) Noticias de Arquitectura (1721-1740). Fuentes para la historia del arte andaluz. Sevilla: Ediciones Guadalquivir, 1993, Tomo VI

- OlLERo lobato, F. (1994) Noticias de Arquitectura (1761-1780). Fuentes para la historia del arte andaluz. Sevilla: Ediciones Guadalquivir, 1994, Tomo XIV 